\title{
Alternative Approach to Conventional River Water Treatment Using Natural Coagulant
}

\author{
Komathy Selvaraj ${ }^{1 *}$, Lariyah Mohd Sidek ${ }^{2}$, Megat Johari Megat Mohd Noor ${ }^{3}$, Pramila Tamunaidu ${ }^{4}$, Masafumi \\ Goto $^{5}$ \\ ${ }^{1}$ Civil Engineering Department, College of Engineering, Universiti Tenaga Nasional, Malaysia \\ ${ }^{2}$ Sustainable Technology and Environment Group, Institute of Energy Infrastructure, Universiti Tenaga Nasional, Malaysia \\ ${ }^{3}$ Malaysia-Japan International Institute of Technology (MJIIT), Universiti Teknologi Malaysia KL \\ *Corresponding author E-mail: komathy.sv@gmail.com
}

\begin{abstract}
Extensive studies have been conducted to discover natural, efficient and cost-saving coagulants for water treatment. Meanwhile, chemical coagulants are being used conventionally in drinking water treatment. This study investigates the efficacy of diatomite as a natural coagulant in river water treatment. First, synthetic turbid water was used to validate the coagulant efficiency. Then, coagulation and flocculation behaviors were studied by using the river water samples from Langat River and Semenyih River. Turbidity removal efficiency of synthetic turbid water revealed that a low dosage of $3.5 \mathrm{mg} / \mathrm{L}$ could reach turbidity reduction of $83.46 \%$. The turbidity reduction for Semenyih River water with initial turbidity of 31.8 NTU was achieved at $91.7 \%$ with $18 \mathrm{mg} / \mathrm{L}$ dosage at pH of 7.4 whereby, for Langat River water with an initial turbidity of $43.3 \mathrm{NTU}$, the turbidity reduction was achieved at $94.5 \%$ with a dosage of $26 \mathrm{mg} / \mathrm{L}$ at $\mathrm{pH}$ of 8.0 . These results showed that water turbidity removal was influenced by both high and low natural organic material. This is because the best dosage of coagulant is indirectly proportional to the molar mass of natural organic material. In conclusion, diatomite is a promising material to be used as a natural coagulant in water treatment applications.
\end{abstract}

Keywords: Coagulation; Diatomite; River Water; Turbidity; Water Treatment.

\section{Introduction}

It has been predicted that global demand for water will increase by approximately $50 \%$ by the year 2030 . In addition to that, it has been estimated that by 2050 , an increment of 2.3 billion people is expected to be suffering from serious water stress [1]. Therefore, researches on water quality are conducted by many scientists around the world as well as in Malaysia [2-8]. In Malaysia, water treatment plant generally starts with aeration process followed by coagulation, flocculation, and sedimentation, as stated by Azzouz and Ballesteros (2013), is effective for removing dissolved organic contaminants present in surface water [9]. Coagulation and flocculation are the key steps for clean water production in a generic water treatment processes. Coagulation is defined as a process of aggregating all the smaller particles into larger flocs which are then removed through subsequent sedimentation process [10]. Flocculation is a process of forming larger particles to assist the sedimentation process of the suspended particles [11]. In this context, many scientists have done studies in investigating the potential of diatomite as a coagulant. Diatomite is a naturally occurring sedimentary rock formed by fossilization of phytoplankton. It is a biodegradable material found abundantly around the world in both fresh and seawater. It is available at a low cost as well. It consists of approximately $87-91 \%$ silicon oxide $\left(\mathrm{SiO}_{2}\right)$, and an estimable amount of alumina $\left(\mathrm{Al}_{2} \mathrm{O}_{3}\right)$ and iron oxide $\left(\mathrm{Fe}_{2} \mathrm{O}_{3}\right)$ [12]. The major component of silica found in diatomite derives from an external cell wall (frustules) formed surrounding the diatoms [13]. This material has driven the interests of scientists for its remarkable physicochemical properties such as high porosity, surface area, and thermal resistance [14-15]. Traditionally, chemical coagulants used in water treatment are aluminum sulfate, ferric and ferrous sulfate [16]. These coagulants are added during coagulation and flocculation process. The previous study has reported on the effectiveness of diatomite in reducing turbidity. As mentioned by Meesuk, Benjamas and Utha-aroon (2008) the natural diatomite from Thailand can be used to remove sugarcane juice color and turbidity in an industrial process [17]. Another studies Turbidity indicates the presence of fine organic and inorganic matter, colored compounds, algae and other microorganisms. It is measured by the relative clarity of a liquid where the intensity of light scattering is directly proportional to turbidity in Nephelometric Turbidity Units (NTU) using turbidimeter [18]. The national drinking water quality standard as implemented by the Ministry of Health, Malaysia (2010) [19]. Thus the objective of this study was to investigate the efficiency of diatomite as a coagulant in coagulation and flocculation process in treating raw water. The optimum dosage of diatomite is also discussed in this paper.

\section{Methodology}

This study was conducted in two phase. The first phase involves the preparation of synthetic turbid water. Synthetic turbid water was used as a preliminary test to validate the coagulant efficiency. In the second phase, the best dosage of coagulant was determined to study the coagulation and flocculation behavior. For the second phase, river water from Sungai Langat and Sungai Semenyih were used as river water with low turbidity (less than 50 NTU). 


\subsection{Coagulant}

The diatomite coagulant was washed with distilled water and airdried. It was then stored in a desiccator to prevent moisture prior to use.

\subsection{Preparation of Synthetic Turbid Water}

The overall methodology of the first phase is as illustrated in Fig. 1. Level of turbidity used in this study was 50 NTU (low turbidity).

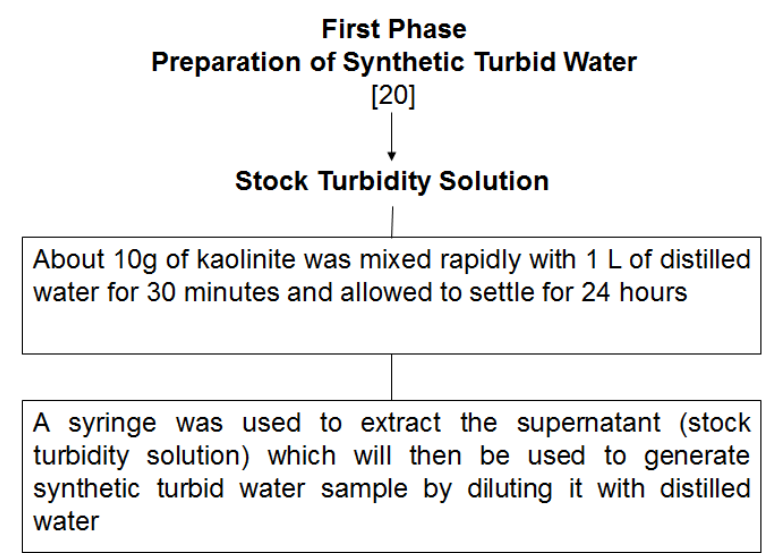

Fig. 1: Flowchart of overall methodology for preparation of synthetic turbid water at an initial turbidity of $50 \mathrm{NTU}$

\subsection{Coagulation/Flocculation Test}

The methods used for jar test and turbidity measurement are conforming to the Standard Practice for Coagulation-Flocculation Jar Test of Water published by ASTM (2003) [23]. The Jar test method is as illustrated below in Fig. 2.

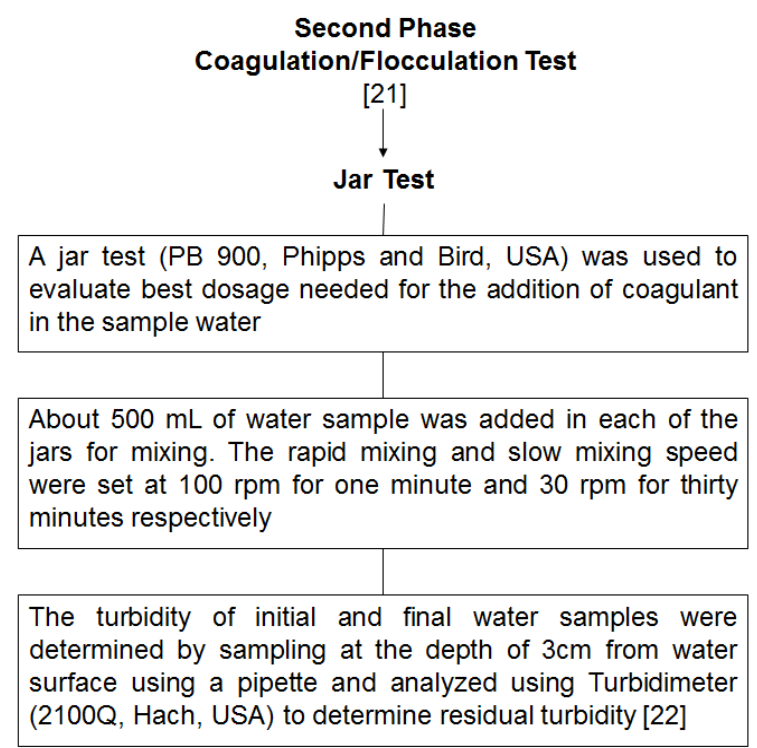

Fig. 2: Flowchart of Jar test procedure to determine the best dosage of coagulant for both synthetic turbid water and river water samples

\section{Results and Discussion}

In this study, the initial phase which is the preliminary test was conducted to study the efficiency of diatomite as a coagulant in treating synthetic turbid water. It was analyzed based on lowest residual turbidity at the best dose. Few parameters were kept constant using jar test likewise (i) simultaneous rapid and slow mixing throughout the test, (ii) clockwise rotation of the paddles, size and speed of each paddle, and also (iii) size of the beakers used.

The varying parameter is the dosage of coagulant used. Fig. 3 showed results of coagulant activity of diatomite at 50 NTU of synthetic turbid water. The lowest peak in the graph shows that a low amount of diatomite dosage of $3.5 \mathrm{mg} / \mathrm{L}$ could reach the turbidity reduction of $83.46 \%$. The coagulant activities were further illustrated by the formation of flocs throughout the settling process lasting approximately 60 mins after the slow mixing process.

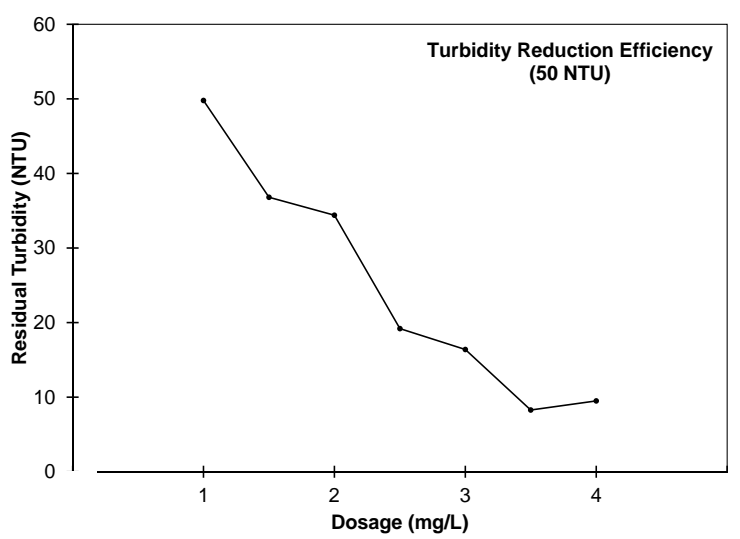

Fig. 3: Turbidity removal efficiency of synthetic turbid water at an initial turbidity of $50 \mathrm{NTU}$

The graph is shown in Fig. 3 revealed that the increment in residual turbidity of synthetic turbid water at a dosage of $4 \mathrm{mg} / \mathrm{L}$ suggests that dosing high amount of coagulant above the best dosage has led to the increase of turbidity. This scenario could be due to charge neutralization mechanism, where dosing of coagulant should be proportional to the removal of organic matter in order to avoid destabilization [24]. The charge neutralization at the best dose allows the positively charged diatomite particles to collide with the negatively charged kaolinite particles thus forming flocs and sediment.

However, overdosing may disrupt the mechanism as it causes charge reversal and destabilization of colloids. The colloids will be positively charged and repulsion of the particles occurs thus increases the turbidity. Furthermore, this destabilization process is rapid that the colloids change from positive to negatively charge and vice versa [25]. Lastly, insufficient dosing and overdosing result in poor performance of diatomite in the flocculation process.

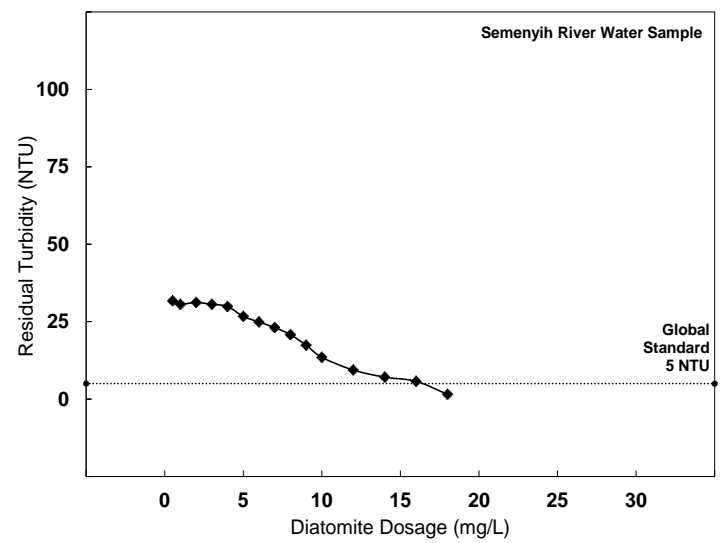

Fig. 4: Turbidity removal efficiency of Semenyih River water at an initial turbidity of $43.3 \mathrm{NTU}$

Moving on to the second phase graph as shown in Fig. 4 and Fig. 5 for the Semenyih River water and Langat River water respectively. The turbidity reduction achieved for Semenyih River water was $91.7 \%$ with the best dosage of $18 \mathrm{mg} / \mathrm{L}$ of diatomite at $\mathrm{pH}$ of 
7.4 whereby, for Langat River water the turbidity reduction achieved was $94.5 \%$ with the best dosage of $26 \mathrm{mg} / \mathrm{L}$ of diatomite at $\mathrm{pH}$ of 8.0 .

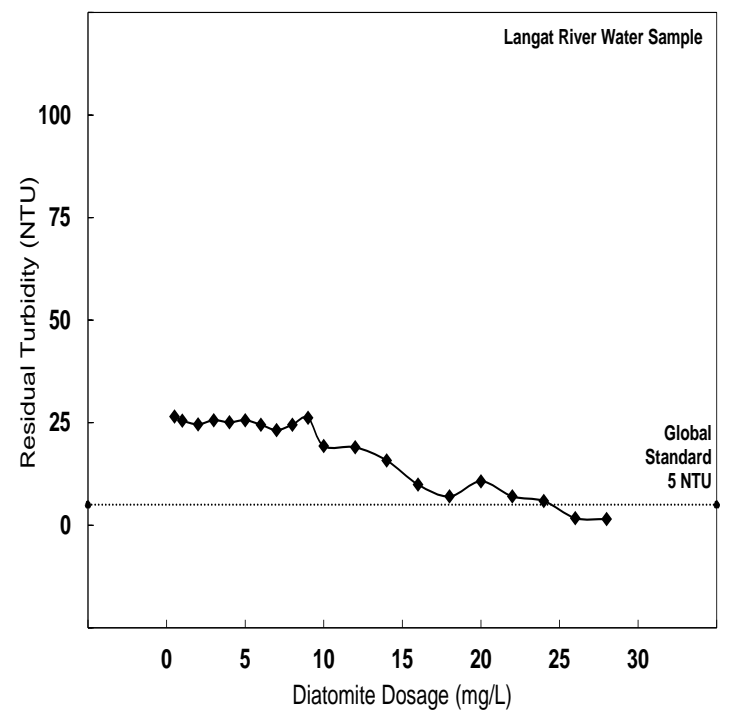

Fig. 5: Turbidity removal efficiency of Semenyih River water at an initial turbidity of 31.8 NTU

In terms of turbidity, Semenyih River water has higher turbidity however the dosage of diatomite required is comparatively lower than the dosage used to treat Langat River water. This phenomenon might be due to the presence of natural organic matter (NOM) where the range of organic components may vary at different origins or same location but seasonally thus affecting the dosage. This is because the best dosage of coagulant may be low for water with high molar mass (HMM) NOM in contrary to NOM with low molar mass (LMM) which requires high dosage. This was supported by Matilainen, Vepsäläinen, and Sillanpää (2010), where the hydrophobic part of NOM is removed effectively than the hydrophilic part [26]. Therefore, HMM components are removed easily than LMM compounds as HMM is hydrophobic in nature, consisting more of aromatic compounds as compared to LMM.

In this case, enhanced coagulation in which excess dosing might be required for the removal of organic matter. This scenario was not applicable to river water as it may contain a high amount of organic matter as compared to synthetic turbid water which contains less organic matter. The organic material particles either resist aggregation or form flocs that have a lower fraction than particle flocculated in the absence of organic matter.

\section{Conclusion}

The synthetic turbid water and river water samples from Semenyih River and Langat River provide sufficient data to study the efficiency of diatomite as a coagulant. The turbidity reduction in synthetic turbid water demonstrated the adsorptive coagulation mechanism, where dosing of coagulant should be proportional to the removal of organic matter in order to avoid destabilization. Whereas, the organic material found in river water sample consists of both high natural organic material and low natural organic material which influence the dosage of diatomite. Since diatomite is an effective coagulant as discussed earlier, therefore, further research should be conducted to review coagulation activity in detail.

\section{Acknowledgement}

The authors would like to express sincere gratitude to Ministry of Higher Education (MOHE) and Universiti Teknologi Malaysia (UTM) for providing Flagship grant (Vote No. 03G24), Malaysia and Japan International Institute of Technology (MJIIT) and
Universiti Tenaga Nasional (UNITEN) for supporting the research.

\section{References}

[1] Guppy L \& Anderson K (2017), "Water crisis report," United Nations University Institute for Water, Environment and Health (UNU-INWEH), Hamilton, Canada. 2017.

[2] Al-Ani IAR, Sidek LM, Desa MMN, Ahmad Basri NE (2012), Knowledge-based expert system for stormwater management in Malaysia. J Environ Sci Technol, Vol. 5, No. 5, 381-388.

[3] Chow MF, Abu Bakar MF, Sidek LM, Basri H (2017), Effects of substrate types on runoff retention performance within the extensive green roofs. J Eng Appl Sci, Vol. 12, No. 21, 5379-5383.

[4] Kok KH, Sidek LM, Abidin MR, Basri H, Muda ZC, Beddu S (2013), Evaluation of green roof as green technology for urban stormwater quantity and quality controls. IOP Conference Series: Earth and Environmental Science, Vol. 16, No. 1, Article Number 012045 .

[5] Ayub KR, Sidek LM, Ainan A, Zakaria NA, Ghani AA, Rozi A (2005), Storm water treatment using bio-ecological drainage system. Int J River Basin Manage, Vol. 3, No. 3, 215-221.

[6] Jajarmizadeh M, Sidek LM, Mirzai M, Alaghmand S, Harun S, Majid MR (2016), Prediction of Surface Flow by Forcing of Climate Forecast System Reanalysis Data. Water Resource Management, Vol. 30, No. 8, 2627-2640.

[7] Norazli O, Nor EA, Muhd NM, Lariyah MS, Nor AO (2009), Potential of electronic plastic waste as a source of raw material and energy recovery. Sains Malaysiana, Vol. 38, No. 5, 707-715.

[8] Lariyah MS, Mohiyaden HA, Hayder G, Hayder G, Hussein A, Basri H, Sabri AF \& Noh MN (2016), Application of Moving Bed Biofilm Reactor (MBBR) and Integrated Fixed Activated Sludge (IFAS) for Biological River Water Purification System: A Short Review, IOP Conference Series: Earth and Environmental Science.

[9] Fai CM, Bakar MFBA, Roslan MAAB, Fadzailah FAB, Idrus MFZB, Ismail NFB (2015), Hydrological performance of native plant species within extensive green roof system in Malaysia. ARPN J Eng Appl Sci, Vol. 10, No. 15, 6419-6423.

[10] Azzouz A \& Ballesteros E (2013), Influence of seasonal climate differences on the pharmaceutical, hormone and personal care product removal efficiency of a drinking water treatment plant. Chemosphere, Vol. 93, 2046-2054.

[11] Zhao S, Huang G, Fu H \& Wang Y (2014), Enhanced Coagulation/Flocculation by Combining Diatomite with Synthetic Polymers for Oily Wastewater Treatment. Separation Science and Technology, Vol. 49, No. 7, 999-1007.

[12] Baghvand A, Zand AD, Mehrdadi N \& Karbassi A (2010), Optimizing Coagulation Process for Low to High Turbidity Waters Using Aluminum and Iron Salts. American Journal of Environmental Sciences, Vol. 6, No. 5, 442-448.

[13] Fatah HM (2015), Pleistocene Stephanodiscaceae Diatoms from Deposits in El Fayoum Depression, Egypt. Vegetos-An International Journal of Plant Research, Vol. 28, No. 2, 15-24.

[14] Ibrahim S \& Selim A (2011), Evaluation of Egyptian diatomite for filter aid applications. Physicochemical Problems of Mineral Processing, 47, 113-122.

[15] Zhao S, Huang G, Fu H \& Wang Y (2014), Enhanced coagulation/flocculation by combining diatomite with synthetic polymers for oily wastewater treatment. Separation Science and Technology, 49, 999-1007.

[16] Bakr HEGMM (2010), Diatomite: Its characterization, modifications, and applications. Asian Journal of Materials Science, 3, 121136.

[17] IWA, "Coagulation and Flocculation in Water and Wastewater Treatment", IWA Publishing, (2018), available online: https://www.iwapublishing.com/news/coagulation-andflocculation-water-and-wastewater-treatment, last visit: 01.07.2018.

[18] Meesuk L, Benjamas A \& Utha-aroon C (2008), The Use of Diatomite to Remove Color and Turbidity in Sugar Industry. Kasetsart J. (Nat. Sci.), 42, 107-116.

[19] Lambrou T, Anastasiou C \& Panayiotou C (2009), A Nephelometric Turbidity System for Monitoring Residential Drinking Water Quality. Sensor Applications, Experimentation, and Logistics, 43-55.

[20] Engineering Services Division, "Drinking Water Quality Surveillance Programme", Ministry of Health, (2010), available online: 
http://kmam.moh.gov.my/public-user/drinking-water-qualitystandard.html, last visit: 02.07.2018.

[21] Raj KS, Noor MJMM, Goto M, Tamunaidu P, "Characterisation and Application of Diatomite in Water Treatment", Proceedings of the Second International Conference on the Future of ASEAN (ICoFA) 2017, Vol.2, (2018), pp:533-539, https://doi.org/10.1007/978-981-10-8471-3_53

[22] Mohammad TA, Mohamed EH, Noor MJMM \& Ghazali AH (2013), Coagulation activity of spray dried salt extracted Moringa oleifera. Desalination and Water Treatment, Vol. 51, No. 7-9, 1941-1946

[23] ASTM D2035-13, Standard Practice for Coagulation-Flocculation Jar Test of Water, ASTM International, (2013)

[24] Tsai WT, Lai CW \& Hsien, KJ (2006), Characterization and adsorption properties of diatomaceous earth modified by hydrofluoric acid etching. Journal of Colloid Interface Science, Vol. 297, No. 2, 749-54

[25] Okuda T, Baes AU, Nishijima W, \& Okada M (2001), Coagulation Mechanism of Salt Solution-Extracted Active Component in Moringa oleifera Seeds. Water Research, Vol. 35, No. 3, 830-834

[26] Matilainen A, Vepsäläinen, M \& Sillanpää M (2010), Natural organic matter removal by coagulation during drinking water treatment: A review. Advances in Colloid and Interface Science, Vol. 159, No. 2, 189-197 